\title{
The Glubran 2 glue for mesh fixation in Lichtenstein's hernia repair: a double-blind randomized study
}

\author{
Stanisław Dąbrowiecki, Stanisław Pierściński, Wojciech Szczęsny \\ Department of General and Endocrine Surgery, Nicolaus Copernicus University, Collegium Medicum, Bydgoszcz, Poland
}

Videosurgery and Other Miniinvasive Techniques 2012; 7 (2): 96-104 DOI: 10.5114/wiitm.2011.27429

\begin{abstract}
Introduction: With an average incidence rate of $11 \%$, chronic pain is considered the most serious complication of inguinal hernioplasty after surgical site infection. One of the proposed solutions to this problem is to use tissue adhesive for mesh fixation, which helps prevent nerve and tissue damage.

Aim: The goal of this study was to compare mesh fixation with the use of sutures vs. adhesive in Lichtenstein's inguinal hernia repair in a randomized, double-blind one-center study.

Material and methods: The study group consisted of 41 males with primary inguinal hernia undergoing Lichtenstein's repair (20-adhesive; 21 - suture) and remaining in follow-up from July 2008 to November 2010. Randomization took place during the operation. The follow-up was performed by one surgeon (blinded) according to a pre-agreed schedule; the end-of-study unblinding was performed during the last follow-up visit, usually 16 months postoperatively.

Results: In 1 patient from the "adhesive" group, a recurrence was observed one year after the initial repair. The early postoperative pain was less intense in this group. In later postoperative periods the method of mesh fixation had no influence on the pain experienced by the patient. Other complications were not correlated with the method of mesh fixation.

Conclusions: In this randomized, one-center double-blind clinical study of males with primary inguinal hernia it has been show during follow-up that the use of Glubran 2 cyanoacrylate adhesive for mesh implant fixation yields similar recurrence and chronic pain rates as the classical suture technique. In the early postoperative period, the pain reported by these patients was relatively weaker; patients undergoing adhesive mesh fixation experienced a quicker return to daily household activities.
\end{abstract}

Key words: inguinal hernia, Lichtenstein procedure, tissue adhesive.

\section{Introduction}

One of the most crucial criteria for successful modern inguinal hernia repair is short recovery time combined with postoperative pain as minor as possible. Despite the evident advancement in the domain, these goals are still unachievable. The occurrence of postoperative chronic pain is especially disturbing as it is felt by $0-43 \%$ of patients, $11 \%$ on average [1].
Postoperative pain is the consequence of tissue dissection and postoperative local inflammation. As a result, the surrounding nerves become damaged and nociceptive stimulation occurs. Surgeon's experience, local complications, synthetic material implantation are considered to be dominant causative factors. Inflammation appears with the ligation of the hernia sack, neurectomy, when a nerve gets captured into a suture or scar around the implant and with 
ischemic testicle. Sutures applied behind the periosteum of the pubic tubercle lead to chronic periostitis, another source of the chronic pain. Surgical access and the way implant is fixed are irrelevant $[2,3]$. Matyja et al. showed that tension-free technique does not influence the incidence of the postoperative pain [4]. Also the comparison of Lichtenstein and Desard technique did not reveal any significant differences in the early postoperative painful sensation [5]. The traditional method of penetrating mesh fixation in the groin has its flaws. Except for bleeding after femoral or epigastric vessels damage caused by a needle, sutures may cause tissue ischemia, muscle contracture and nerve damage. The change may be the source of postoperative and chronic pain. Remission of the chronic ailments after sutures are removed in the evidence of cause and effect reliance [6]. Attempts have been made to replace nonabsorbable with absorbable sutures, but clinical trials did not show any significant differences $[7,8]$. Similarly, staples or tackers caused new dangers, but did not relieve pain [9]. There are numerous articles on the prevention and pain occurrence after inguinal hernia repair in the literature. Reports concerning chronic pain after hernia repair are especially disturbing. Pain is diversely defined. In the following report, the British Pain Society definition was accepted: chronic pain is continuous pain, lasting over 12 weeks or - in case of surgical procedures or damages - it is pain occurring after tissues have healed. According to the International Association for the Study of Pain (IASP), chronic pain is recognized when it occurs after the surgery and lasts minimum 2 months. This definition is criticized as it does not take into account changes occurring later on when the pain starts to decrease gradually e.g. due to the termination of inflammation. Such sequence of events may be expected in hernioplasty: after tissue structures have been strengthened by synthetic material. Those issues are recapped in the newest reports [10]. Apposition of tissues without excessive tension is a relatively new factor mentioned, which corresponds to the experience of the surgical team. Too energetic surgical maneuvers (the strength applied here amounts up to $20 \mathrm{~N}$ ) causes micro damages of the surrounding tissue which activates painful sensations occurring regardless of other prophylactic treatment. Two groups of patients should be acknowledged in pain assessment: young people, professionally and physically active and middle-aged or old- er patients with limited physical activity. The risk of chronic pain occurrence in the $2^{\text {nd }}$ group is significantly lower [11]. Recently, the methods of implant fixation have been discussed during meetings. Penetrating (staplers/tackers) and adhesive (sealants) methods of fixation are compared and situations when an implant does not have to be fixed to the surrounding tissues are defined. The first indexed report dates back to 1984 . Russian doctors, Shapkina et al. used cyanoacrylic sealant in surgery in children. One hundred and eight hernioplasties were performed with good results [12]. The next trials were performed a decade later by Farouk et al. who modified Lichtenstein method by fixing the mesh with cyanoacrylic adhesive in grown-up patients. No recurrences were observed in the $1^{\text {st }}$ year after the surgery [13].

The results achieved using a fibrin sealant, created by mixing fibrinogen component with a thrombin solution, were presented for the first time by Canonico et al. The method was employed in patients with coagulation disturbances (1999), and next in healthy patients and professional athletes [14-16]. To determine a valid conclusion different methods of mesh fixation have to pass through all the phases of clinical trials. Having considered the importance of the issue and its practical implications on the one hand, and lack of reliable clinical information with regard to the usage of cyanoacrylic sealant (3 indexed randomised control trials - RCTs), on the other hand, we started our own, maintaining the highest possible methodological standard prospective, randomized, doubleblind clinical trial (both a physician and patient).

\section{Material and methods}

Fourty-one male patients with primary inguinal hernia, operated on using Lichtenstein technique from July 2008 to November 2010 were included in the trial in the Department of General and Endocrine Surgery, Nicolaus Copernicus University, Collegium Medicum in Bydgoszcz. The inclusion criteria were as follows: age $\geq 21$ years old, male sex, primary inguinal hernia (in case of contralateral hernia, one side was selected for the study). Patients aged below 21 years, with a recurrent or incarcerated hernia, after attempted reduction of a hernia (with hospital stay), with a postoperative scar in the area of the planned procedure, cryptorchism, varices of the spermatic cord (clinical trial - no such cases were observed), degen- 
erative spine diseases or other pathologies causing pain radiating to the abdomen and groin were excluded from the study. Patients who did not fully understand the nature of the study or did not give their consent to participate were also excluded.

The trial was planned according to the following scheme:

- patient selection (verification of diagnosis, assessment of inclusion and exclusion criteria),

- acquainting the patient with the schedule and goals of the clinical trial,

- patient's consent to treatment supported by patient's signature on an informed consent form,

- routine preparation for the procedure; fractionated heparin only in patients previously receiving anticoagulant treatment, without antibiotic prophylaxis,

- the procedure performed using Lichtenstein method - the course of the procedure identical in all patients until mesh fixation,

- intraoperative randomization,

- mesh implantation; soaking the mesh in 80 ml gentamicin/250 $\mathrm{ml}$ physiological saline solution before placement [17],

- finalizing the procedure and registering surgical variables,

- follow-up appointments on the $2^{\text {nd }}$ (hospital discharge), $7^{\text {th }}$ (suture removal), 30th $60^{\text {th }}, 180^{\text {th }}$ and $360^{\text {th }}$ postoperative day.

Randomization was prepared with the use of software available at http://www.randomization.com/ (1st generator was employed). Information concerning mesh fixation was available in sealed envelopes in the operating room. During mesh fixation stage, randomly chosen envelope was opened and the information was discreetly passed to the surgeon so that the conscious patient would not be aware of the surgeon's proceedings. Data concerning mesh fixation ware gathered in a separate database, but were excluded from the surgical protocol, patient's history and release form. The way nerves were handled in the surgical field was described in each case (ilioinguinal nerve, hypogastric nerve and genital branch of genitofemoral nerve were always identified). Whether the nerve was left intact or excised was recorded in the database. Prolene (Ethicon) polypropylene mesh sized $15 \mathrm{~cm} \times 7-10 \mathrm{~cm}$ was employed (its transverse size adapted to patient's anatomy). Glubran sealant (N-butyl-2-cyanoacrylate; GEM S.r.l., Viareggio, Italy) was used according to the manufacturer's instructions. Points of sealing approximated typical areas where sutures were placed, $1 \mathrm{~mm}$ was used each time. In the "suture" series, the mesh was fixed to the inguinal ligament with the continuous 2-0 polypropylene suture, and to the aponeurosis of the internal oblique muscle with single 2-0 PDS sutures. Closing off the inguinal canal, sutures for the subcutaneous tissue and suturing the skin were identical in both groups. The procedures were performed by 4 surgeons $(26,10,4$ and 1 procedure). The method of anesthesia was not standardized. The patient decided in agreement with the anesthesiologist on the basis of the clinical situation. The procedures were performed under general, subarachnoid or local anesthesia (50 : 50 mixture of 1\% lidocaine and $0.25 \%$ bupivacaine). In the postoperative period, ketoprofen was administered and in case of contraindications - tramadol. Doses of analgesics used were recorded. Patients were evaluated during follow-up appointments by a surgeon who did not know the method used and had no access to documentation. Patients had scheduled checkups, but in practice, with time they became less self-disciplined and the appointments got postponed. The initial tests took place 1 day before the procedure (they were marked as -1 ), the first checkup on the $2^{\text {nd }}$ postoperative day. The actual median values for the subsequent follow-up appointments were: $10^{\text {th }}, 32^{\text {th }}$, $78^{\text {th }}, 202^{\text {nd }}$ and $401^{\text {st }}$ postoperative day (Table I). In the description below, the following designations were used: $-1^{\text {st }}, 2^{\text {nd }}, 7^{\text {th }}, 30^{\text {th }}, 80^{\text {th }}, 200^{\text {th }}$ and $400^{\text {th }}$ postoperative day.

During the follow-up appointments, all complications, sensation disturbance, foreign body sensation and sexual dysfunction were notified. Return to driv-

Table I. Planned and actual follow-up periods

\begin{tabular}{|cccc|}
\hline $\begin{array}{c}\text { Scheduled } \\
\text { appointment } \\
\text { (post-operative day) }\end{array}$ & \multicolumn{3}{c|}{$\begin{array}{c}\text { Actual date of the appointment } \\
\text { (days after procedure) }\end{array}$} \\
\cline { 2 - 4 } & Median & Min-max & $1^{\text {st-3rd quartile }}$ \\
\hline-1 & -1 & - & - \\
\hline 2 & 2 & $1-6$ & $2-3$ \\
\hline 7 & 10 & $7-14$ & $9-11$ \\
\hline 30 & 32 & $25-63$ & $31-36$ \\
\hline 60 & 78 & $54-107$ & $65-95$ \\
\hline 180 & 202 & $120-532$ & $187-234$ \\
\hline 360 & 401 & $330-849$ & $370-591$ \\
\hline
\end{tabular}


ing, typical house chores, work and sport was recorded. Visual Analog Scale (VAS) scale was used to assess pain. On a $10 \mathrm{~cm}$ scale the patient marked the point corresponding to the pain intensity $(0-$ no pain whatsoever, 10 - agonizing pain). The distance from the beginning of the scale was measured in $\mathrm{mm}$ translating VAS into verbal assessment. It was assumed after Jensen et al. that 0-4 $\mathrm{mm}$ mean no pain, 5-44 $\mathrm{mm}$ mean mild pain, 45-74 $\mathrm{mm}$ moderate pain and over 75 sever pain [18]. In some cases patients were unable to unambiguously determine the intensity of pain sensation. Unblinding the patient and physician took place during the last follow-up appointment - on average 16.7 months after the procedure. The above described trial was accepted by the Nicolaus Copernicus University's Bioethical Commission (201/2008).

\section{Statistical analysis}

Normality distribution of variables was assessed and adequate parametric and non-parametric tests were employed. For a normal distribution, average value and standard deviation were used, for nonparametric distribution - median and $1^{\text {st }}$ and $3^{\text {rd }}$ quartile [always in square brackets]. VAS determination, repeated several times, was analyzed by ANOVA (Analysis of Variance) Friedman test. Differences between groups were tested by Mann-Whit- ney $U$ test and by Pearson's $\chi^{2}$ statistics with Yates correction, correlation of variables - with Spearman Rank correlation test. Values of $p<0.05$ were accepted as statistically significant.

\section{Results}

Randomized, clinical, double-blind trial (patient, physician) was carried out in 41 patients. It assessed the results of surgical treatment in patients with primary inguinal hernia using the polypropylene mesh fixed with sutures or Glubran 2 adhesive. Twenty patients had mesh fixed with sealant (sealant group) and 21 - traditionally with sutures (suture group). Demographic and surgical variables did not fundamentally differ in both groups (Table II).

In the early postoperative period, in 4 cases, hematoma was observed in the body area where the procedure was performed, in 2 cases leakage of serum content from the wound, and in 1 - inflammatory infiltration (similarly in both groups). All the complications were treated using conservative methods. The patients operated on with sealant stayed in hospital a bit shorter (median: 2 vs. 3 days; $p=0.06$ ). Until hospital discharge, both groups took similar amounts of analgesics. In 1 patient who had mesh fixed with sealant, hernia recurred 1 year after the procedure - it was confirmed by USG (sealant group vs. suture group, $p=0.767$ )

Table II. Demographic data and details of the surgery in both groups

\begin{tabular}{|lccc|}
\hline Variable & $\begin{array}{c}\text { Sealant group } \\
(n=20)\end{array}$ & $\begin{array}{c}\text { Suture group } \\
(n=21)\end{array}$ & Value of $p$ \\
\hline Average age \pm standard deviation & $47.4 \pm 13.4$ & $45.4 \pm 14.8$ & 0.67 \\
\hline Manual work/headwork/no work & $10 / 5 / 5$ & $10 / 7 / 4$ & 0.31 \\
\hline VAS before procedure & $35.0[15 ; 40]$ & $23.0[12 ; 30]$ & 0.23 \\
\hline Hernia right side/left & $10 / 10$ & $11 / 10$ & 0.88 \\
\hline Local/subarachnoid/general anesthesia & $16 / 1 / 3$ & $17 / 4 / 0$ & 0.91 \\
\hline Hernia type oblique/straight/both & $12 / 8 / 0$ & $15 / 5 / 1$ & 0.35 \\
\hline Width of hernia ring 1/2/3 fingers & $8 / 8 / 4$ & $11 / 8 / 2$ & 0.26 \\
\hline Dissected hernia sac/reduced & $2 / 18$ & $5 / 16$ & 0.40 \\
\hline Inguinal nerves ${ }^{\star}$ dissected/intact & $16 / 4$ & $16 / 5$ & 0.87 \\
\hline Length of hospital stay & $2[2-4]$ & $3[2-6]$ & 0.06 \\
\hline$*$ least on of 3 nerves & & & \\
\hline
\end{tabular}

${ }^{*}$ At least one of 3 nerves 
Table III. Pain severity on individual days of the postoperative period

\begin{tabular}{|ccccc|}
\hline \multirow{2}{*}{$\begin{array}{c}\text { Pre/postoperative } \\
\text { day }\end{array}$} & \multicolumn{4}{c|}{ Pain intensity } \\
\cline { 2 - 5 } & No pain & Mild & Moderate & Severe \\
\hline-1 & 7 & 27 & 6 & 1 \\
\hline 2 & 0 & 13 & 22 & 1 \\
\hline 7 & 0 & 30 & 4 & 1 \\
\hline 30 & 12 & 19 & 1 & 0 \\
\hline 80 & 18 & 9 & 1 & 0 \\
\hline 200 & 17 & 9 & 2 & 0 \\
\hline 400 & 24 & 7 & 0 & 0 \\
\hline
\end{tabular}

Classification according to [18]

Table IV. Return to normal activity levels in both groups

\begin{tabular}{|c|c|c|c|}
\hline \multirow[t]{2}{*}{$\begin{array}{l}\text { Return to } \\
\text { activities }\end{array}$} & $\begin{array}{l}\text { Sealant group } \\
\quad(n=20)\end{array}$ & $\begin{array}{l}\text { Suture group } \\
\qquad(n=21)\end{array}$ & \multirow[t]{2}{*}{$\begin{array}{l}\text { Value } \\
\text { of } p\end{array}$} \\
\hline & \multicolumn{2}{|c|}{ Median [1st-3rd quartile], days } & \\
\hline Daily & $3[2-4]$ & $5[4-7]$ & 0.003 \\
\hline Professional & 40 [30-90] & $40[30-60]$ & 0.31 \\
\hline Sport & 30 [30-40] & 35 [30-45] & 0.27 \\
\hline Driving & $7[5-14]$ & 7 [7-14] & 0.74 \\
\hline
\end{tabular}

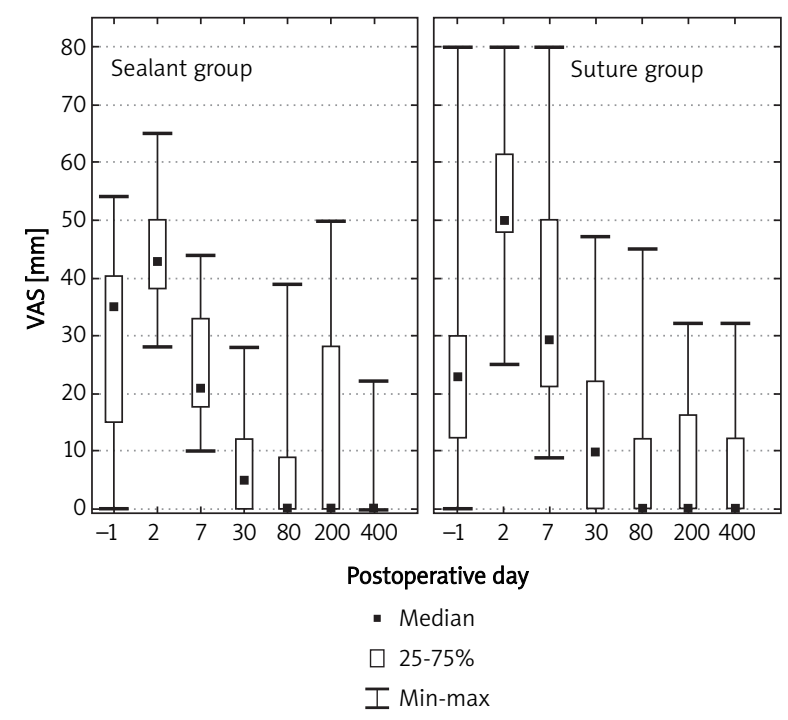

Figure 1. A summary of VAS pain scores upon subsequent follow-up visits

\section{Postoperative pain}

Before the procedure pain intensity on a VAS scale ranged $0-80 \mathrm{~mm}$, on average $28 \pm 19 \mathrm{~mm}$ (Table I). Pain intensity measurements according to Jensen classification in the intraoperative and later period are presented in Table III [18]. Before the surgery, the number of patients without pain was equaled by the number of those with moderate and severe pain $(n=7)$. The most numerous group consisted of patients with mild pain $(n=27)$. In the postoperative period, pain intensity changed. ANOVA results for all the patients and both subgroups were statistically significant $(p<0.001)$ until the $30^{\text {th }}$ postoperative day. Later on, VAS measures did not differ; pain intensity was similar. Translating VAS into subjective ailments, it could be observed that on the $2^{\text {nd }}$ and $7^{\text {th }}$ postoperative day every patient felt pain; on the $2^{\text {nd }}$ day as many as 22 patients felt pain of moderate intensity. Only on the $7^{\text {th }}$ day mild pain was predominating $(n=30)$. During the next follow-up appointments, pain intensity in practice did not change; between the $80^{\text {th }}$ and the $400^{\text {th }}$ day the same people felt constant pain of similar, mild intensity.

No relations between pain intensity and the method of mesh fixation were observed on the 30th or later postoperative day (only patients with mild and moderate pain, numbers bolded in Table III). When comparing the postoperative course in both groups, different significant values of pain intensity were observed on the $2^{\text {nd }}$ postoperative day (Figure 1). In the sealant group, pain was relatively less intense than in the suture group (VAS, sealant group vs. suture group, $43 \mathrm{~mm}$ vs. $50 \mathrm{~mm}$ respectively, $p<0.05$ ). In Figure 1, also on the $7^{\text {th }}$ day, the disparity of VAS values is visible (median differs almost by 10 points), but the big interquartile range in the suture group precludes grasping the significant difference.

Smaller painful ailments after using sealant in the early postoperative period are confirmed by significantly shorter time necessary for return to daily activities (Table IV). Return to professional activity depended on the kind of job done; the time was significantly longer in the group of manual workers (median: $45 \mathrm{vs.}$ 30 days; $p<0.05$ ). Return to daily activities, sport and driving was similar in both groups.

In patients with minimum of 2 nerves in the groin cut, the time necessary to return to work was shorter (median: 30 vs. 45 days, $p=0.02$ ). However, if the pain is assessed on a VAS scale at the same postop- 
erative time (around 60-80 day), there is no difference between the compared groups. In patients who had 1 of the nerves in the groin cut, the time of recovery was not statistically different from the ones with intact nerves. No significant differences or increase of sexual disorder occurrence in the compared groups were observed in the pre- or postoperative period. While examining correlations between values of variables, a significant reliance was observed between pain intensity measures on a VAS scale on $2^{\text {nd }}$ and $7^{\text {th }}$ postoperative day and the return to everyday activities (both cases $R=0.4, p<0.05$ ). Pain intensity correlated positively on the $2^{\text {nd }}$ and $7^{\text {th }}$ and $200^{\text {th }}$ and 400th postoperative day (in both cases $R=0.45$, $p<0.05)$. There was no correlation between preoperative pain and its postoperative values (VAS scale).

\section{Discussion}

The randomized, single-center, double-blind clinical trial including male patients with primary inguinal hernia operated on using Lichtenstein method and observed from 11 months to 28 months (median: 16.4 months) showed that polypropylene mesh fixation with Glubran 2 cyanoacrylic sealant allows achieving similar results in the case of chronic pain recurrence to standard mesh fixation with sutures. In the early postoperative period in patients with sealant used, painful ailments were relatively less intense (VAS scale, $2^{\text {nd }}$ day); patients operated on in such way came back earlier to everyday activities. The differences appeared also on the $7^{\text {th }}$ postoperative day, but they were statistically insignificant. Although, it is believed that uncomplicated inguinal hernia do not cause painful ailments, it is not supported by studies. In our own observations, patients felt pain of an average VAS value of $28 \pm 19 \mathrm{~mm}$, which corresponds to mild pain. These values are higher than quoted by Page et al. [19]; in their trial fewer patients with moderate and severe preoperative pain were included. In a multicenter study by Paajanen et al., in the identical group of patients, preoperative pain was of higher intensity - it corresponded to $4.0 \pm 2.4$ on a VAS scale [20]. EHS congress in 2011 confirmed increasing interest in non-penetrating mesh fixation. The results of such procedures in inguinal and abdominal hernia repair were discussed. Nowadays, in medicine numerous tissue adhesives are used: biological, synthetic and genetically engineered proteinaceous ones (Table V).
Cyanoacrylic adhesives are synthetic sealants firstly employed in medicine. They were synthesized in 1942 by Harry Coover in Kodak laboratories when he was searching for a super clean yielding material for rifle datives. After a few unsuccessful applications, Kodak created "Eastman \#910" glue out of the product. In 1964, as a result of Kodak and Ethicon's studies, it was submitted to Food and Drug Administration (FDA) as an agent for closing wounds. Since 1966 the sealant was used in the Vietnam War. Used at the battle ground in the form of spray, it stopped bleeding very successfully. According to veterans of this war, it saved many lives. Otherwise, soldiers would have bled to death. It is ironic, but FDA forbade the use of the adhesive. It did not prevent its use during the war, though [21]. FDA did not approve of the sealant because of skin irritation it caused and its reaction with water which released cyanoacetate and formaldehyde. Only 2-octyl-cyanoacrylate met the expectations; it caused less skin irritations and it bound the tissues better than previously synthesized compounds. In 1998, FDA approved this compound for wound closing, and in 2001 - as antibacterial barrier. The product was introduced to the market as Dermabond. There are many cyanoacrylic adhesives available for different uses. The majority of them are non-absorbable, characterized by cytotoxicity and polymerization at high temperature. Some cyanoacrylic adhesives are used in the medical industry: N-butyl-1,2- cyanoacrylate (Histoacryl, B. Braun), 2-octyl-cyanoacrylate (Dermabond, Ethicon), N-butyl2-cyanoacrylate (Indermil, Covidien) and N-hexylcyanoacrylate (Glubran 2, Ifabond, Fimed, France). Glubran 2 sealant used in the trial is characterized by fast polymerization, and the accompanying chemical reaction does not cause the temperature rise above $45^{\circ} \mathrm{C}$. Its low viscosity facilitates application through a catheter. It is gradually absorbed, without an excessive foreign-body reaction. It is very effective; $1 \mathrm{ml}$ is enough for bilateral hernia. Experimental investigations provide contradictory information about Glubran adhesive safety. Fortelny et al. revealed that tissue integration with a mesh was impaired in the area where the sealant was used. The adhesive induced local, excessive inflammation and its remains stiffened tissues - the abdominal wall of a rat [22]. Losi et al. on the same experimental model observed mild inflammation with a small number of macrophage and well supplied with blood connective tissue around the adhesive and mesh filaments. Sealant 
Table V. Commercially available tissue glues, including their composition and brand names

\begin{tabular}{|c|c|c|c|}
\hline Origin & Contents & Commercial names & Choice \\
\hline \multirow[t]{4}{*}{ Biological } & Biological or fibrin adhesive & $\begin{array}{l}\text { Tissucol } \\
\text { Briplast } \\
\text { Tachosil } \\
\text { Quixil }\end{array}$ & Hematogenous medicinal product \\
\hline & Fibrin autologous preparation & $\begin{array}{l}\text { Vivostat } \\
\text { Magellan }\end{array}$ & Medicinal product class III \\
\hline & Bovine gelatin and thrombin & Floseal & \\
\hline & Porcine gelatin & Surgiflo & \\
\hline \multirow[t]{2}{*}{ Semisynthetic } & $\begin{array}{l}\text { Glutaraldehyde } \\
\text { Bovine albumin }\end{array}$ & Bioglue & \\
\hline & $\begin{array}{l}\text { Formaldehyde } \\
\text { Glutaraldehyde } \\
\text { Porcine gelatin } \\
\text { Resorcinum }\end{array}$ & GRF & \\
\hline \multirow[t]{4}{*}{ Synthetic } & Polyethylene glycol & & \\
\hline & Polyethylene glycol & Coseal & \\
\hline & Cyanoacrylate & $\begin{array}{l}\text { Glubran } \\
\text { Ifabond } \\
\text { Omnex }\end{array}$ & \\
\hline & & $\begin{array}{l}\text { Dermabond } \\
\text { Histoakryl } \\
\text { Indermil }\end{array}$ & Medicinal product class Ila \\
\hline
\end{tabular}

remains were visible in the whole 5 -month observation period [23]. The newest, still awaiting publication, results of Kukleta's research showed that after a year Optline LP mesh fixed in the rabbit's abdominal wall with histoacryl was faster integrated than one fixed with MonoPlus 3-0 sutures. After a year, the adhesive was absorbed completely and its local tolerance was assessed as good [24]. The clinical literature concerning cyanoacrylic adhesive in open hernia surgeries in grownups is rather scarce. There are 7 indexed publications altogether, and two of them pertain to laparoscopy $[25,26]$. The first prospective, randomized report comparing cyanoacrylic sealant with sutures was presented by Helbling et al. [8]. No evident differences in pain sensation were observed after 3 months with a slight tendency towards decrease in ailments in the adhesive group. Testini using Rytkow technique in 156 patients observed that chronic pain occurred only in 3.4\% of the operated on with sutures; in the series with sealant (fibrin or cyanoacrylic) it did not occur at all [27]. In a Nowobil- ski et al. trial no fundamental differences were observed in the postoperative course within 4.7 months in patients operated on using Lichtenstein technique with sealant (Indermin, Loctite) and sutures [28]. The value of the report is decreased by the fact that authors do not write about randomization or control in patients. In a short report concerning the same series of patients (however with different numerical amount) there is information about 1 recurrent hernia in a sealant group [29]. A report by Paajanen et al. may be used to benchmark our own results, as they randomized Glubran $(n=151)$ and Dexon 3-0 $(n=151)$ fixation in a multicenter study. Procedures were performed on an outpatient basis, Optilene mesh was implanted, oblique hernia sac was dissected. During 1 year observation, hernia recurred twice in each group (1.4\%). Chronic pain (VAS $\geq 2$, over 3 months) in patients from both groups occurred with the similar frequency (sealant vs. sutures, $20 \%$ vs. $15 \%$ respectively). It was demonstrated that chronic pain depended on preoperative pain occurrence, patient's 
age and the length of the procedure; the method of mesh fixation was irrelevant [20]. The results of clinical assessment did not reveal fundamental differences between a sealant and sutures. With a corresponding definition of the chronic pain patient, our own results do not diverge from the quoted observations $(22 \%$ of patients with chronic pain). Penetrating and adhesive fixation was compared more often in laparoscopic TAPP than in open surgeries. Three RCT and 5 controlled clinical trials were published. It was observed that adhesive fixation reduces recurrence $(0.4 \%$ vs. $0.6 \%$ ) and painful sensations (in 4 out 5 trials).

For example, Olmi et al. compared different techniques of fixation in a large series of patients. They showed the superiority of fibrin sealant over penetrating fixation [30]. Kukleta's clinical experience is also convincing. He performed 1337 transabdominal pre-peritoneal (TAPP) procedures using only Glubran 2 adhesive fixation [31]. Results of previous trials (however, mostly concerning TAPP) reveal that sealant fixation reduces the risk of chronic pain in comparison to staplers/tackers (grade of recommendation 1B). It is not without significance that biological and synthetic sealants are less expensive than devices for penetrating fixation. Our own research, carried out in a series of patients operated on through an anterior approach, did not reveal fundamental differences between adhesive and penetrating fixation. With the similar results of 16-month observation, it was demonstrated that adhesive mesh fixation may have positive influence on the early postoperative period.

\section{References}

1. Nienhuijs S, Staal E, Strobbe L, et al. Chronic pain after mesh repair of inguinal hernia: a systematic review. Am J Surg 2007; 194: 394-400

2. Nienhuijs SW, Rosman C, Strobbe LJ, et al. An overview of the features influencing pain after inguinal hernia repair. Int I Surg 2008; 6: 351-6

3. Amid PK. Lichtenstein tension-free hernia repair: its background and evolution with focus on avoiding postherniorrhaphy chronic pain. Videosurgery and Other Miniinvasive Techniques 2009; 4: 26-31.

4. Matyja A, Kibil W, Pach R, et al. Assessment of inguinal hernia treatment results in patients operated on with mesh using Lichtenstein, PHS and Robbins-Rutkow techniques. Videosurgery and Other Miniinvasive Techiques 2010; 5: 27-34.

5. Szczęsny W, Szopiński J, Reśliński A, et al. Early postoperative pain after Lichtenstein and Desarda hernioplasty. Chirurg Pol 2010; 12: 67-75.
6. Amid PK. Causes, prevention, and surgical treatment of postherniorrhaphy neuropathic inguinodynia: triple neurectomy with proximal end implantation. Hernia 2004; 8: 343-9.

7. Paajanen H. Do absorbable mesh sutures cause less chronic pain than nonabsorbable sutures after Lichtenstein inguinal herniorraphy? Hernia 2002; 6: 26-8.

8. Helbling C, Schlumpf R. Sutureless Lichtenstein: first results of a prospective randomised clinical trial. Hernia 2003; 7: 80-4.

9. Mills IW, McDermott IM, Ratliff DA. Prospective randomized controlled trial to compare skin staples and polypropylene for securing the mesh in inguinal hernia repair. Br J Surg 1998; 85: 790-2.

10. Alfieri S, Amid PK, Campanelli G, et al. International guidelines for prevention and management of post-operative chronic pain following inguinal hernia surgery. Hernia 2011; 15: 239-49.

11. Kehlet H. Laparoscopic versus open groin hernia repair: are we getting closer to specific clinical recommendations? Hernia 2010; 14: 553-4.

12. Shapkina AP, Kravtsov I. Method of surgical treatment of inguinal hernias in children using glue [Russsian]. Vestn Khir Im I I Grek 1984; 133: 100-3.

13. Farouk R, Drew PJ, Qureshi A, et al. Preliminary experience with butyl-2-cyanoacrylate adhesive in tension-free inguinal hernia repair. Br J Surg 1996; 83: 1100.

14. Canonico S, Benevento R, Della Corte A, et al. Sutureless tension-free hernia repair with human fibrin glue (tissucol) in soccer players with chronic inguinal pain: initial experience. Int J Sports Med 2007; 28: 873-6.

15. Canonico S, Santoriello A, Campitiello F, et al. Mesh fixation with human fibrin glue (Tissucol) in open tension-free inguinal hernia repair: a preliminary report. Hernia 2005; 9: 330-3.

16. Canonico S, Sciaudone G, Pacifico F, et al. Inguinal hernia repair in patients with coagulation problems: prevention of postoperative bleeding with human fibrin glue. Surgery 1999; 125: 315-7.

17. Deysine M. Postmesh herniorrhaphy wound infections: can they be eliminated? Int Surg 2005; 90 (3 Suppl): S40-4.

18. Jensen MP, Chen C, Brugger AM. Interpretation of visual analog scale ratings and change scores: a reanalysis of two clinical trials of postoperative pain. J Pain 2003; 4: 407-14.

19. Page B, Paterson C, Young D, et al. Pain from primary inguinal hernia and the effect of repair on pain. Br J Surg 2002; 89: 1315-8.

20. Paajanen H, Kössi J, Silvasti S, et al. Randomized clinical trial of tissue glue versus absorbable sutures for mesh fixation in local anaesthetic Lichtenstein hernia repair. Br J Surg 2011; 98: 1245-51.

21. Singer AJ, Thode HC Jr. A review of the literature on octylcyanoacrylate tissue adhesive. Am J Surg 2004; 187: 238-48.

22. Fortelny RH, Petter-Puchner AH, Walder N, et al. Cyanoacrylate tissue sealant impairs tissue integration of macroporous mesh in experimental hernia repair. Surg Endosc 2007; 21: 1781-5.

23. Losi P, Burchielli S, Spiller D, et al. Cyanoacrylate surgical glue as an alternative to suture threads for mesh fixation in hernia repair. J Surg Res 2010; 163: e53-8.

24. Kukleta JF, Freytag C, Weber M. Efficiency and safety of mesh fixation in laparoscopic inguinal hernia repair using n-butryl-2cyanoacrylate glue: long-term biocompatibility in over 1,300 mesh fixations. Hernia 2011 Epub ahead of print. 
25. Jourdan IC, Bailey ME. Initial experience with the use of $\mathrm{N}$-butyl 2-cyanoacrylate glue for the fixation of polypropylene mesh in laparoscopic hernia repair. Surg Laparosc Endosc 1998; 8: 291-3.

26. Miyano G, Yamataka A, Kato Y, et al. Laparoscopic injection of dermabond tissue adhesive for the repair of inguinal hernia: short- and long-term follow-up. J Pediatr Surg 2004; 39: 1867-70.

27. Testini M, Lissidini G, Poli E, et al. A single-surgeon randomized trial comparing sutures, $\mathrm{N}$-butyl-2-cyanoacrylate and human fibrin glue for mesh fixation during primary inguinal hernia repair. Can J Surg 2010; 53: 155-60.

28. Nowobilski W, Dobosz M, Wojciechowicz T, et al. Lichtenstein inguinal hernioplasty using butyl-2-cyanoacrylate versus sutures. Preliminary experience of a prospective randomized trial. Eur Surg Res 2004; 36: 367-70.

29. Dobosz M, Nowobilski W. Further study of tissue adhesive. Hernia 2004; 8: 404.

30. Olmi S, Scaini A, Erba L, et al. Quantification of pain in laparoscopic transabdominal preperitoneal (TAPP) inguinal hernio plasty identifies marked differences between prosthesis fixation systems. Surgery 2007; 142: 40-6.

31. Kukleta J. Personal communication, 33rd International Congress of the European Hernia Society, Ghent, Belgium May 2011. 